\title{
Resenha de Gomes (2017). O Movimento Negro educador: saberes construídos nas lutas por emancipação
}

Marcos Antonio Batista da Silva

Universidade de Coimbra

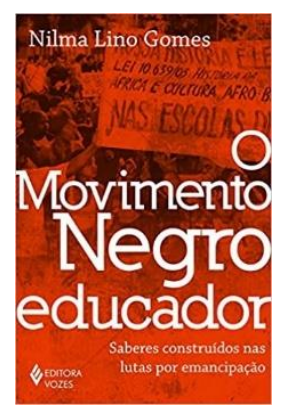

Gomes, Nilma Lino (2017). O

Movimento Negro educador:

saberes construídos nas lutas

por emancipação. Vozes, $154 \mathrm{p}$.

ISBN: 978-85-326-5579-0

Nilma Lino Gomes é professora de graduação e pós-graduação da Universidade Federal de Minas Gerais (UFMG), Brasil. Possui mestrado em Educação pela UFMG, doutorado em Antropologia Social pela Universidade de São Paulo (USP), e pós-doutorado em Sociologia, pela Universidade de Coimbra (UC), Portugal, e Universidade Federal de São Carlos (UFSCar), São Paulo, Brasil. Foi reitora protempore da Universidade Internacional da Lusofonia Afro-Brasileira (Unilab), ministra da Secretaria de Políticas de Promoção da Igualdade Racial e do Ministério das Mulheres, da Igualdade Racial e do Ministério das Mulheres, da Igualdade Racial, da Juventude e dos Direitos Humanos do governo da Presidenta Dilma Rousseff no Brasil. É autora de diversas obras na área educacional, com ênfase nas relações étnico-raciais, de gênero e educação, formação de professores para a diversidade e Movimento Negro e saberes.

Neste livro muito especial, Nilma Gomes apresenta como tese principal o papel do Movimento Negro brasileiro como educador e como tal, produtor de saberes emancipatórios, e um sistematizador de conhecimentos sobre a questão racial 
no Brasil. Apesar dos avanços nos campos institucional, legal e social no que se refere à promoção da igualdade racial, entende-se que este livro é uma contribuição importante, necessária e oportuna para a promoção da igualdade racial, para a consolidação da consciência negra, e um exercício diário de cidadania para todos/as.

Segundo a autora, o entendimento dos saberes produzidos pelos movimentos sociais negros (Movimento Negro, Movimento de Mulheres Negras), entre outros, é capaz de subverter a teoria educacional, contruir a pedagogia das ausências e das emergências, repensando a escola, a universidade e descolonizando os currículos. Nesta direção, o conteúdo deste livro encontra seu lugar na sociedade e cumpre seu principal papel, o de auxiliar no combate as desigualdades sociais e ao racismo na sociedade brasileira e construindo uma consciência negra, ou seja, uma população negra, que se assume e se autodeclara negra, buscando resgatar e valorizar sua cultura, origem e o pensamento afro-brasileiro, bem como denuncia veementemente o racismo, através da mídia, além do acesso às redes sociais, que amplificam o alcance dessas vozes, bem como pelo reconhecimento do Estado, que nas últimas décadas tem adotado políticas públicas educacionais de promoção da igualdade racial, e em particular, as ações afirmativas e a Lei $n^{\circ}$ 10.639/2003 que versa sobre o ensino da História e Cultura Afro-brasileira e Africana, frutos de décadas de lutas do Movimento Negro na sociedade brasileira.

O Movimento Negro educador, o assunto abordado por Nilma Gomes, também se relaciona à minha trajetória pessoal e acadêmica de pesquisador e à reduzida atenção dada ao tema, a despeito de sua importância na academia, tema discutido por Sales Augusto dos Santos (2011). Eu me autodeclaro negro, e tive desde a infância um convívio com narrativas sobre questões relacionadas ao racismo e às desigualdades sociais. Contudo, esta preocupação se tornou mais evidente à medida que a minha trajetória educacional se desenvolveu. Com o ingresso, na academia, novos dilemas se apresentam, isto é, conflitos que são elaborados quando estudantes negros enfrentam um modelo burguês, branco, de atividade intelectual que nos coloca na defensiva. "O peso desse fardo inescapável para alunos negros no meio acadêmico branco muitas vezes tem determinado o conteúdo e caráter da atividade intelectual negra" (Hooks, 1995, p. 472).

As pesquisas da história das mobilizações da população negra no Brasil contribuem para que a sociedade brasileira principalmente no período democrático recente. Referimo-nos, portanto, ao século XXI seja reconhecida como uma sociedade na qual o racismo e as desigualdades raciais estão presentes. Encarar o debate sobre desigualdades raciais historicamente acumuladas e socialmente reproduzidas no Brasil se apresenta, ainda, como um desafio de grandes 
proporções, pois significa examinar a fundo o próprio projeto de nação que vem sendo construído desde tempos remotos (sociedade colonial).

De um lado, convivem, no Brasil, de maneira tensa, a cultura e o padrão estético negro, em contraposição a um padrão estético e cultural do branco europeu. Ainda persiste no Brasil um imaginário étnico-racial que privilegia a branquitude, em particular no contexto da universidade, majoritariamente branca, e que historicamente está constituída como espaço de reprodução da branquitude (L. Cardoso, 2010). De outro, observa-se, o desenvolvimento de programas de valorização da cultura da população afro-brasileira e indígena em especial no âmbito educacional (educação básica e ensino superior). A herança do passado escravista não pode ser omitida quando se trata das desigualdades educacionais no país, o qual está associado à manutenção de um sistema político e educacional pouco democrático que reforçam as intensas desigualdades sociais.

Embora as políticas públicas educacionais já estejam em vigor no país, em especial as Leis $\mathrm{n}^{\circ} 10.639 / 03$, e suas "Diretrizes Curriculares Nacionais para a Educação das Relações Étnico-Raciais e para o Ensino de História e Cultura AfroBrasileira e Africana" (Conselho Nacional de Educação, 2004), ainda há uma certa resistência de algumas instituições em adotá-las. Nota-se a falta de discussão das questoões étncio-raciais em particular em contextos acadêmicos (universidades), principalmente no que se refere ao currículo educacional.

O livro de Nilma Gomes tem sete capítulos, a saber: 1) 0 movimento Negro Brasileiro como ator político; 2) Pedagogias que emergem; 3) O Movimento Negro e os saberes; 4) Tensão regulação-emancipação, produção de conhecimentos e saberes;5) Corporeidade negra e tensão regulação-emancipação social: corpo negro regulado e o corpo negro emancipado; 6) Tensão dialética e crise do pilar regulação-emancipação sociorracial no campo das relações raciais e educação; 7) Movimentos sociais, Movimento Negro e subjetividades desestabilizadoras. Novos horizontes emancipatórios? Nesta direção, em seu prefácio, Boaventura de Sousa Santos assinala que "A perspectiva privilegiada por Nilma Gomes para mostrar a riqueza epistemológica do Movimento Negro é a educação" (Santos, 2017, p. 10).

Na introdução, Nilma Lino Gomes (2017, p. 13) frisa que "O Movimento Negro é um educador" e nos revela que sua trajetória acadêmica (ensino e pesquisa), foi pautada neste reconhecimento, e lança algumas questões que orientaram a obra em questão, a saber:

0 que a Pedagogia e as práticas pedagógicas teriam a aprender com o Movimento Negro entendido como ator político e educador? [...]. O que os currículos têm a aprender com os processos educativos construídos pelo 
Movimento Negro ao longo da nossa história social, política e educacional? A pós-graduação dialoga com esses aprendizados? (Gomes, 2017, p. 13)

Tais questões segundo a autora, são frutos de um aprendizado e representam de um lado, "um tributo ao investimento intelectual, político, de vida", e de outro, “à trajetória persistente e tensa construída por tantos militantes do Movimento Negro", em especial, mulheres negras que lutaram e lutam pela superação do racismo na sociedade brasileira, bem como "pela construção da emancipação social no Brasil e na diáspora africana" (Gomes, 2017, p. 13).

No primeiro capítulo intitulado "O movimento Negro Brasileiro como ator político", Nilma Gomes discorre sobre esse movimento social no Brasil reafirmando a sua importância e realizações, e enfatiza que ao resignificar e politizar afirmativamente a ideia de raça, esse movimento social indaga a própria história do Brasil e da população negra brasileira. "A raça é aqui entendida como construção social que marca, de forma estrutural e estruturante, as sociedades latino-americanas, em especial, a brasileira” (Gomes, 2012, p. 727).

Entende-se que o termo raça, foi ressignificado pelo Movimento Negro que, em várias situações, o utiliza com um sentido político e de valorização do legado deixado pelos africanos, isto é, o conceito de raça ao ser utilizado com conotação política permite, por exemplo, aos negros valorizar a característica e romper com as teorias raciais que foram formuladas no século XIX e até hoje permeiam o imaginário popular. Para a autora, a discussão sobre raça no Brasil e nos mais variados contextos não se faz no isolamento. "Antes se articulam às questões históricas, sociais, culturais, políticas e econômicas mais amplas” (Gomes, 2012, p. 729).

A história do negro no Brasil, traz para o convívio da sociedade determinações histórica de exclusão. Mas a partir da denúncia do mito da democracia, especialmente na década de 1970 , o país testemunhou uma ampla mobilização em torno da questão racial, com destaque das diversas entidades do Movimento Negro, trazendo o tema de volta à arena política, fazendo com que os governantes que até então não tinham demonstrado atenção, se atentassem aos problemas das desigualdades raciais. Os anos 1980 marcam o avanço nas lutas dos trabalhadores por direitos sociais, quando as reivindicações dos movimentos sociais ecoam na sociedade (resistência). Como resultado dos ativismos social e político do Movimento Negro, no âmbito da Constituição Federal de 1988.

A partir da segunda metade da década de 1990 uma série de medidas começam a serem tomadas pelo poder público federal, impulsionadas pela "Marcha Zumbi dos Palmares contra o racismo". A pressão dos movimentos sociais (Movimento Negro) e da sociedade civil organizada também impulsionam o atendimento por 
uma educação de valorização da população negra e indígena. 0 início do governo do presidente Luiz Inácio Lula da Silva, em 2003, marca uma mudança profunda não só na condução das políticas de combate à desigualdade racial, reflexo da "Conferência de Durban". Pela primeira vez, na história do país, é criada uma Secretaria Especial, com status de ministério, responsável pela implementação de políticas públicas para a superação das desigualdades raciais no Brasil.

No início do governo Lula, é assinada a Lei $n^{\circ} .10639 / 2003$, que torna obrigatório o ensino da História e Cultura Afro-brasileira e Africana nos estabelecimentos de ensino da educação básica. Se o primeiro mandato desse governo é marcado pela promulgação dessa Lei, destaca-se no segundo mandato, a promulgação da Lei 11.645/2008 (ensino da História e Cultura Afro-brasileira e Indígena) reconhecendo assim, a semelhança de suas experiências históricas e sociais.

Vale mencionar que se tem na atualidade no Brasil, mais de uma década de políticas de ação afirmativa desenvolvidas em instituições de ensino superior, visando à garantia de acesso de grupos racializados (indígenas, negros) em cursos de graduação, institucionalizada com a aprovação da Lei n ${ }^{\circ}$. 12.288/10 (Estatuto da Igualdade Racial), e Lei ${ }^{\circ}$. 12.711/2012 (Lei sobre as cotas nas universidades institutos técnicos federais). Portanto, a seletividade persistente do sistema educacional brasileiro justifica a adoção de políticas de ação afirmativa no ensino superior na sociedade brasileira. Entende-se as políticas de ação afirmativa como uma intervenção em tempo delimitado, do Estado ou do setor privado, visando ao aumento acelerado da presença de membros de grupos racializados em esferas da vida social (educação, política, trabalho) e com vistas à promoção da igualdade racial, buscando corrigir os efeitos presentes da discriminação racial e do racismo, de modo a concretizar o ideal de efetiva igualdade de acesso a bens fundamentais e direitos de cidadania plena.

No segundo capíutlo: "Pedagogias que emergem”, Nilma Gomes frisa que "apesar da grande participação dos movimentos sociais como forma de organização da sociedade civil e de pressão sobre o Estado, nem todos ganharam a mesma visibilidade social política e acadêmica no cenário brasileiro" (Gomes, 2017, p. 40). Ancorada por estudo de Boaventura Sousa Santos (2004) a autora indica que "a percepção dessa ausência não acontece por acaso. Questioná-la poderá ser um caminho interessante para a mudança do enfoque das pesquisas [...] sobretudo no campo educacional" (Gomes, 2017, p. 40).

O terceiro capítulo: “O Movimento Negro e saberes", inicia com uma ênfase ao Movimento Negro, da autora, “o Movimento Negro contemporâneo, enquanto movimento social, pode ser compreendido como um novo sujeito coletivo e político que, juntamente com os outros movimentos sociais, emergiu de forma mais orgânica”, na decáda de 1970" no Brasil (Gomes, 2017, p. 47). Na esteira de Eder 
Sader (1988), Nilma Gomes (2017, p. 47) assinala que "Enquanto sujeito coletivo, esse movimento é visto [...] como uma coletividade onde se elaboram identidades e se organizam". Observa-se ainda, nesse capítulo, um diálogo da autora com Marcos Cardoso (2002), isto é, de acordo com M. Cardoso (2002), " no caso do Movimento Negro, o que marca uma profunda diferença entre este e o conjunto dos demais movimentos sociais e populares nessa época é história" (Gomes, 2017, p. 48). Desse modo, "para o Movimento Negro, o cotidiano da população negra é determinado pela estrutura do racismo na sociedade brasileira". Isto é, "o Movimento Negro buscou na história a chave para a compreender a realidade do povo negro brasileiro" (Gomes, 2017, p. p. 48).

Nilma Gomes (2017) concorda com M. Cardoso (2002) "que emergência do Movimento Negro como um novo personagem na cena brasileira significa um contraponto à realidade racial do nosso país, constituindo-se uma outra possibilidade de entendimento do real" (Gomes, 2017, p. 48). Entretanto Gomes (2017, p. 48) assinala que "nem sempre esse outro ponto de vista tem sido [...] considerado, sobretudo pela escola, cuja reflexão crítica, histórica e social da realidade brasileira deveria ser um dos principais aspectos dos currículos após a ditadura". Ainda segundo Gomes (2017), "essa lacuna na interpretação crítica sobre a realidade racial brasileira e sobre as lutas empreendidas pela população negra" visando o combate ao racismo, "tem impelido o Movimento Negro de demandar e exigir da escola práticas pedagógicas e curriculares" que valorizem a história a cultura e o pensamento afro-brasileiro no espaço educacional (Gomes, 2017, pp. 48-49).

No quarto capítulo: "Tensão regulação-emancipação, produção de conhecimentos e saberes", Nilma Gomes, ancorada nos estudos de Boaventura de Sousa Santos, dá ênfase aos desafios da tensão regulação-emancipação para a produção de conhecimentos e saberes na construção de uma pedagogia pós-abissal.

O pensamento pós-abissal parte do reconhecimento de que a exclusão social, no seu sentido mais amplo, assume diferentes formas conforme seja determinada por uma linha abissal ou não-abissal, e da noção de que enquanto persistir a exclusão definida abissalmente não será possível qualquer alternativa pós-capitalista progressista. (Santos, 2007, p. 84)

Segundo Nilma Gomes

Saberes emancipatórios produzidos pelos negros e pela negras e sistematizados pelo Movimento Negro [...] Trata-se de uma maneira de conhecer o mundo, da produção de uma racionalidade marcada pela vivência da raça numa sociedade racializada desde o início da sua conformação social. (Gomes, 2017, p. 67) 
Para autora, dada a importância da raça na constituição da sociedade brasileira que "esses saberes deveriam fazer parte da educação escolar, dos projetos educativos não escolares e do campo do conhecimento de maneira geral" (Gomes, 2017 , p. 68) principalmente após a obrigatoriedade da Lei $n^{\circ} 10.639 / 03$ (ensino de História e Cultura Afro-brasileira e Africana) no sistema educacional brasileiro.

Neste capítulo, Nilma Gomes apresenta ainda uma breve reflexão sobre o conhecimento e saber, e aborda os saberes produzidos pela comunidade negra e sistematizados pelo Movimento Negro Brasileiro: os saberes identitários (o Movimento Negro, especialmente no contexto das políticas de ações afirmativas, recoloca o debate sobre raça no Brasil e o resisgnifica); os saberes políticos (o Estado, sobretudo o Ministério da Educação, passam a tematizar sobre as desigualdades étnico-raciais); os saberes estéticos-corpóreos (esses saberes tangem à estética da arte, à estética como forma de sentir o mundo, como forma de viver o corpo). Para Gomes (2017, p. 77), estes saberes "estão interligados de maneira dinâmica, apesar de suas especificidades".

No quinto capítulo: “Corporeidade negra e tensão regulação-emancipação social: corpo negro regulado e corpo negro emancipado", a autora ancorada pelas teorias (sociológica e antropológica), dá ênfase a forma como o corpo foi introduzido pelos estudos feministas e pós-estruturalistas, ao discutir sobre os estudos que focalizam o corpo e em articulação com a discussão sobre Movimento Negro e projetos educativos emancipatórios (Gomes, 2006). "No Brasil, o corpo negro ganha visibilidade social na tensão entre adaptar-se, revoltar-se ou superar o pensamento racista que o toma por erótico, exótico e violento" (Gomes, 2017, p. 94). A autora frisa que essa superação ocorre mediante a "publicização da questão racial como um direito, via práticas, projetos, ações políticas, cobrança do Estado e do mundo privado" (Gomes, 2017, p. 94).

Nilma Gomes questiona: "Qual é a especificidade do corpo negro nos processos de regulação-emancipação social? Que tipo de corpo esses processos podem produzir?" (Gomes, 2017, p. 96). Segundo a autora, o corpo pode ser "regulado" de duas formas: a dominante (escravizado, objeto, estereotipado), e dominada (o corpo cooptado pelo dominante) entre outros. Quando Nilma Gomes escreve sobre a tensão regulação- emancipação do corpo negro, ela destaca que "o processo de regulação do corpo negro se deu (e ainda se dá) de maneira tensa e dialética com a luta pela emancipação social empreendida pelo negro enquanto sujeito" (Gomes, 2017, p. 98).

Por sua vez, no sexto capítulo: "Tensão dialética e crise do piar regulação-emancipação sociorracial no campo das relações raciais e educação", a autora apresenta três situações dialética, além da crise do "pilar regulação-emancipatória 
sociorracial" no campo das relações raciais (Gomes, 2017, p. 101), a saber: o processo da abolição da escravatura ; a estética negra e as ações afirmativas. Nesta resenha não será possível abarcar toda esta discussão, mas no que se refere as políticas de ação afirmativa, entende-se que ao fim da primeira década do Século XXI, no Brasil, as ações afirmativas podem ser consideradas, em seu conjunto, uma política pública que, efetivamente, tem colaborado para a inclusão de grupos racializados (população negra, povos indígenas) na educação e no trabalho.

No sétimo capítulo: "Movimentos sociais, Movimento Negro e subjetividades desestabilizadoras", Nilma Gomes apresenta um panorama para analisar quais as pautas que o Movimento Negro trouxe para o debate na sociedade brasileira. Entende-se que o Movimento Negro, trouxe entre outras pautas, uma agenda que alia política de reconhecimento, política de identidade, política de cidadania e política redistributiva. Nilma Gomes reafirma ainda que:

O Movimento Negro constrói um projeto educativo emancipatório e, dentro deste, socializa os saberes construídos pela população negra ao longo de sua trajetória histórica. Esses saberes são fruto de subjetividades desestabilizadoras construídas na trajetória dos negros, das negras e nos seus corpos. Subjetividade que foram passadas de geração em geração como herança, cultura e resistência. (Gomes, 2017, p. 130)

Nas considerações finais, Nilma Gomes traz questões, uma característica da autora no decorrer do livro: "Que contribuições traz esse estudo para a pedagogia e para o pensamento educacional? E para o campo das ciências humanas e sociais?” (Gomes, 2017, p. 133). Além de enfatizar alguns pontos: a escola (educação básica e ensino superior/pós-graduação); a pedagogia da diversidade em conexão com o Movimento Negro. Para a autora "A pedagogia da diversidade é uma pedagogia da emancipação" (Gomes, 2017, p. 136).

Contudo, entende-se que o livro situa um debate necessário na sociedade contemporânea, no campo das Ciências Humanas, principalmente no âmbito da educação sobre a questão racial no Brasil. De maneira geral o livro aqui apresentado, contribui para entender o papel do Movimento Negro brasileiro como educador e produtor de saberes emancipatórios sobre a questão racial no Brasil, de maneira que se faz um convite ao leitor para ler esta obra de Nilma Lino Gomes. 


\section{REFERENCIAS}

Cardoso, Lourenço. (2010). Branquitude acrítica e crítica: A supremacia racial e o branco anti-racista. Revista Latinoamericana de Ciencias Sociales, Niñez y Juventud, 8(1), 607-630.

Cardoso, Marcos (2002). O Movimento Negro. Mazza.

Conselho Nacional de Educação (2004). Resolução $n^{\circ}$ 1. Diário Oficial da União, Brasília, 22 jun. 2004, Seção 1, p. 11. http://portal.mec.gov.br/cne/arquivos/pdf/res012004.pdf

Constituição da República Federativa do Brasil de 1988. (1998). Brasília. https://www2.senado.leg.br/bdsf/bitstream/handle/id/518231/CF88_Livro_EC91_2 016.pdf

Gomes, Nilma Lino (2006). Sem perder a raiz: corpo e cabelo, símbolos da identidade negra. Autêntica.

Gomes, Nilma Lino (2012). Movimento negro e educação: ressignificando e politizando a raça. Educação \& Sociedade, 33(120), 727-744. https://doi.org/10.1590/S010173302012000300005

Gomes, Nilma Lino (2017). O Movimento Negro educador: saberes construídos nas lutas por emancipação. Vozes.

Hooks, bell. (1995). Intelectuais Negras. Revista Estudos Feministas, 3(2), 464.

Lei no 10.639/03 (2003). Presidência da República. Diário Oficial da União, Brasília, 10 de janeiro de 2003. http://www.planalto.gov.br/ccivil_03/LEIS/2003/L10.639.htm

Lei $n^{\circ}$ 11.645/08 (2008). Presidência da República. Diário Oficial da União, Brasília, 11 de março de 2008. http://www.planalto.gov.br/ccivil_03/_Ato20072010/2008/Lei/L11645.htm

Lei 12.711/12 (2012). Presidência da República. Diário Oficial da União, Brasília, 30 ago.2012. http://www.planalto.gov.br/ccivil_03/_ato20112014/2012/lei/l12711.htm

Sader, Eder. (1988). Quando novos personagens entram em cena. Paz e Terra.

Santos, Sales Augusto dos (2011). A metamorfose de militantes negros em negros intelectuais. Revista Mosaico, 3(5), 102-125.

Santos, Boaventura de Sousa (Org.) (2004). Conhecimento prudente para uma vida decente. Cortez.

Santos, Boaventura de Sousa (2007). Para além do pensamento abissal: das linhas globais a uma ecologia de saberes. Novos estudos CEBRAP, 79, 71-

94. https: / / doi.org/10.1590/S0101-33002007000300004

Santos, Boaventura Sousa (2017). Prefácio. In: Nilma Lino Gomes (Ed.), O Movimento Negro educador: saberes construídos nas lutas por emancipação (pp. 9-12). Vozes. 


\section{MARCOS ANTONIO BATISTA DA SILVA}

Centro de Estudos Sociais, Universidade de Coimbra. Doutor em Psicologia Social pela Pontifícia Universidade Católica de São Paulo (PUC-SP). Pós-doutorado no Centro de Estudos Sociais, Univ Coimbra (Projeto 725402 - POLITICS - ERC-2016-COG). marcos.psico@yahoo.com.br https://orcid.org/0000-0003-2701-0316

\section{FORMATO DE CITACIÓN}

Silva, Marcos Antonio Batista da (2020). Resenha de Gomes (2017). O Movimento Negro educador: saberes construídos nas lutas por emancipação. Quaderns de Psicologia, 22(3), e1601. http://dx.doi.org/10.5565/rev/qpsicologia.1601 